\title{
The -2548G/A polymorphism in the human leptin gene promoter region is associated with plasma free leptin levels; interaction with adiposity and gender in healthy subjects
}

\author{
Nikos Yiannakouris ${ }^{1}$, Labros Melistas ${ }^{1}$, Mary Yannakoulia ${ }^{1}$, Keisha Mungal $^{2}$, \\ Christos S. Mantzoros ${ }^{2}$
}

${ }^{1}$ Departments of Home Economics and Ecology and Nutrition-Dietetics, Harokopio University, 17671 Athens, Greece, ${ }^{2}$ Division of Endocrinology and Metabolism, Department of Medicine, Beth Israel Deaconess Medical Center, Harvard Medical School, Boston, Massachusetts 02215, USA

\begin{abstract}
A common -2548G/A promoter variant of the human leptin gene has recently been shown to be associated with variations in circulating leptin levels but available data are still conflicting. The aim of this study was to explore potential associations between the $-\mathbf{2 5 4 8 G / A}$ polymorphism and adiposity-related variables, plasma total leptin levels, as well as soluble leptin receptor (sOB-R) levels and free leptin in a group of healthy Greek subjects. One hundred eighteen consecutively enrolled subjects [62 females, 56 males; mean age \pm SD: $17.7 \pm 1.8$ years; body mass index (BMI) range: $15.4-35.9 \mathrm{~kg} / \mathrm{m}^{2}$ ] were genotyped for the $-2548 \mathrm{G} / \mathrm{A}$ polymorphism and their $\mathrm{BMI}$, fat free mass, \% fat mass, fasting plasma total leptin and sOB-R levels were determined. The ratio leptin/ sOB-R was used as an index of free leptin. No significant differences in genotype and allele frequencies of the - 2548G/A polymorphism were detected between normal weight and overweight subjects, and no association was found between this polymorphism and BMI, fat mass or plasma total leptin levels. However, the $\mathbf{- 2 5 4 8 G / A}$ polymorphism was found to be associated with circulating free leptin levels in a gender specific manner. More specifically, compared to carriers of the -2548G allele, female subjects with the $\mathrm{A} / \mathrm{A}$ genotype had higher age and fat mass adjusted mean $( \pm \mathrm{SE})$ plasma concentrations of $\mathrm{SOB}-\mathrm{R}(32.9 \pm 7.2 \mathrm{vs} .25 .6 \pm 3.8 \mathrm{ng} / \mathrm{ml}, P=0.05)$, and significantly lower (approx. 50\%) leptin/sOB-R values $(0.74 \pm 0.25$ vs. $1.42 \pm 0.13, P=0.02)$. Furthermore, multiple regression analysis revealed that, after adjustment to fat mass, the $\mathbf{- 2 5 4 8 G / A}$ genotype and gender are significantly associated with free leptin index in the entire study sample. Similar regression models revealed a significant interaction of gender and genotype when considered in addition to fat mass, or fat mass and genotype when considered in addition to gender, as predictors of free leptin index. In conclusion, the common $\mathbf{- 2 5 4 8 G / A}$ promoter variant of the human leptin gene is associated with plasma free leptin levels through an interaction with adiposity and gender in healthy subjects.
\end{abstract}

Key words: leptin gene variants, soluble leptin receptor, free leptin, fat mass. 


\section{INTRODUCTION}

Circulating concentrations of leptin reflect the amount of energy stored in fat and correlate positively with indices of adiposity. However, individuals with a similar degree of adiposity exhibit great variations in plasma leptin concentrations ${ }^{1-3}$. Hormonal and nutritional factors as well as the recently identified specific soluble leptin receptor (sOB-R) ${ }^{4-6}$ have been proposed as influencing total as well as free leptin concentrations in humans ${ }^{7,8}$.

Furthermore, in addition to the infrequent mutations of the leptin gene resulting in morbid obesity in the ob/ob mouse model of obesity ${ }^{9}$, as well as a few rare cases of obesity in humans ${ }^{10,11}$, genetic variation in the regulatory region of the human leptin gene may partially explain the underlying interindividual differences in leptin levels and may play a role in human obesity $^{12-15}$.

Several sequence variants have been detected within the $5^{\prime}$ flanking region of the human leptin gene ${ }^{12,16}$. One of these polymorphisms, a common $-2548 \mathrm{G} / \mathrm{A}$ leptin promoter variant, has previously been shown to be associated with either variations in serum leptin levels or the degree of obesity in obese and overweight subjects ${ }^{12-16}$. However, the reported data are conflicting. Mammés et $\mathrm{al}^{12}$, found that the less frequent $-2548 \mathrm{~A}$ allele is associated with higher leptin levels at baseline $(P=0.04)$, irrespective of BMI, and that the $-2548 \mathrm{G} / \mathrm{A}$ polymorphism predicts weight loss in response to a low calorie diet. In a subsequent study ${ }^{13}$, the same researchers reported that male, but not female, subjects homozygous for the -2548 A allele had higher leptin concentrations adjusted for fat mass $(P=0.05)$. Recently, Hoffstedt et $\mathrm{al}^{14}$ found that nonobese women with the A/A genotype had higher serum leptin levels adjusted for BMI $(P=0.03)$ and significantly higher adipose tissue leptin mRNA levels $(P=0.01)$ than did carriers of the $-2548 \mathrm{G}$ allele. In another study, Le Stunff et $\mathrm{al}^{15}$ also reported evidence of association between this genetic variant and circulating leptin levels in two independent cohorts of obese Caucasian girls, but in contrast with the previous two studies $^{13,14}$, girls with the A/A genotype (referred to as -/-genotype) exhibited lower mean leptin levels compared to those with G/A and G/G genotypes (20-25\% lower, $P<0.02)$.

The discordant observations in these studies could be attributed to age related and/or gender specific effects of the polymorphism ${ }^{14,15}$. In addition to the potential confounding effect of age and gender, it has also been suggested that fat mass and gender may play a role as effect modifiers ${ }^{15}$. Finally, it is also possible that sOB-R, not measured in the previous studies, may also confound or modify the association between leptin and the polymorphism of interest. Leptin circulates both in bound and free form and both sOB-R (the main leptin binding protein in plasma and determinant of free leptin), as well as the fraction of free/ total leptin, vary according to gender and in several physiological and metabolic states including adiposity ${ }^{4-6}$. No previous studies have explored the association of sequence variants in the regulatory region of the leptin gene with plasma leptin concentrations after adjusting for sOB-R and no previous studies have explored whether gender and fat mass may play a role as effect modifiers of this association.

In order to explore whether the discordant observations of the previous studies ${ }^{12-15}$ are due to one or more of the above reasons, we studied the associations between the $-2548 \mathrm{G} / \mathrm{A}$ polymorphism of the leptin gene promoter, not only with total leptin but also with sOB-R and free leptin. This study utilizes data from a homogeneous sample of young healthy subjects of different genetic background than that of subjects enrolled in previous studies, and also includes, as a negative control, another polymorphism of the leptin gene promoter $(-188 \mathrm{C} / \mathrm{A})$, previously found not to be associated with obesity, serum leptin levels or other obesity-related traits ${ }^{17}$.

\section{SUBJECTS AND METHODOLOGY}

Subjects. One hundred twenty, consecutively enrolled, Greek high-school students participated in this study. They were all investigated in the morning after an overnight fast. Blood samples were obtained in all but two subjects, leaving 118 subjects ( 62 females and 56 males, mean age \pm SD: $17.7 \pm 1.8$ years) for subsequent analysis. Plasma was immediately frozen at $-70^{\circ} \mathrm{C}$ until shipped, under code for analyte determination, packed in dry ice. The buffy coats of nucleated cells were used for the extraction of DNA. Anthropometric and body composition measurements were performed in all study participants. In addition, participants were asked to complete specific self-administered questionnaires on demographic characteristics, general health status, daily exercise, as well as smok- 
ing and alcohol drinking habits. All subjects were healthy. None was on regular medication or had undertaken any weight-reduction effort during the last six-month period. All female participants reported themselves as having regular menstrual cycles. The protocol of this study was approved by the Ethics Committee of Harokopio University. Written informed consent was obtained from all subjects and their parents.

Anthropometry and body composition assessment. Standardized procedures were used in performing anthropometric and body composition measurements, as previously described ${ }^{18}$. For all subjects, weight and height were measured to the nearest $0.5 \mathrm{~kg}$ and 0.5 $\mathrm{cm}$, respectively, and the body mass index (BMI) was calculated as weight (kilograms) divided by height (meters) squared. Waist, hip and arm circumferences were also measured to a precision of $0.1 \mathrm{~cm}$, and the waist-to-hip $(\mathrm{W} / \mathrm{H})$ ratio was calculated. In addition, triceps, biceps, subscapular and suprailic skinfolds were measured twice by the same observer on the right side of the body to a precision of $0.2 \mathrm{~mm}$, and the average of the two measurements was used. Body composition was assessed by bioelectrical impedance analysis, and fat free mass (FFM) and percent fat mass $(\% \mathrm{FM})$ were calculated as previously described ${ }^{18}$.

Leptin and sOB-R measurements. Plasma total leptin concentrations (nanograms per milliliter) were evaluated in one run using radioimmunoassay (RIA) (Linco Research, St Louis, MO) with a sensitivity of $0.5 \mathrm{ng} / \mathrm{ml}$, as previously described ${ }^{18,19}$. Soluble leptin receptor (sOB-R) concentrations $(\mathrm{ng} / \mathrm{ml})$ were evaluated using a commercially available enzyme-linked immunosorbent assay (ELISA) (BioVendor Laboratory Medicine, Inc., Brno, Czech Republic), with a sensitivity of $0.8 \mathrm{ng} / \mathrm{ml}$ and an intra-assay CV of less than $6 \%$, as previously described ${ }^{19}$. The characteristics of the assay for sOB-R were evaluated extensively and compared with those obtained using a newly developed ligand-immunofunctional assay (LIFA) ${ }^{19,20}$.

DNA analysis. Genomic DNA was extracted from leukocyte nuclei as previously described ${ }^{18}$. The human leptin gene promoter -2548G/A genotype was determined after restriction fragment length polymorphism (RFLP) analysis of polymerase chain reaction (PCR) amplified DNA, as described by Mammés et $\mathrm{al}^{13}$. The polymorphism was defined by presence (when $\mathrm{G}$ at position -2548 from the transcription initiation site of the leptin gene) or absence (when A) of a $C f o$ I restriction site $^{13}$. The leptin gene promoter $-188 \mathrm{C} / \mathrm{A}$ genotype was determined by PCR-RFLP analysis, as described by Oksanen et $\mathrm{al}^{17}$. The common allele with the presence of a Bss H II cutting site at position -188 (presence of a $\mathrm{C}$ at position -188) was designated as $\mathrm{C}$, and the variant allele lacking this site $(-188 \mathrm{~A})$ as allele $\mathrm{A}^{17}$.

Statistical analysis. Statistical analyses were performed using the SPSS statistical software (SPSS for windows, release 10.0.5). Descriptive statistics are presented as mean values \pm standard deviation (SD). Allele frequencies were estimated by the gene counting method, and differences in genotype distributions or allele frequencies were tested by chi-square analysis. Associations of quantitative traits with genotype variables were tested by analysis of covariance (General Linear Model procedure), adjusting for age and gender, plus fat mass (or BMI) for leptin, sOB-R and the ratio leptin/sOB-R used as an index of free leptin. Both codominant and recessive for the less common allele models were accessed. Non-normally distributed variables were log-transformed prior to analysis to normalize their distribution, though untransformed mean values are presented. The potential role of the $-2548 \mathrm{~A} / \mathrm{G}$ polymorphism, fat mass and gender in predicting leptin and leptin/sOB-R values was examined using multiple regression analyses. In these analyses, the leptin gene promoter -2548 genotype was introduced as a dichotomous variable; subjects who were homozygous for the less common $-2548 \mathrm{~A}$ allele were compared with subjects who carried at least one $-2548 \mathrm{G}$ allele (i.e. a recessive model for $-2548 \mathrm{~A}$ ). This study had more than $80 \%$ power to demonstrate statistically significant associations at the conventional $\mathrm{a}=0.05$ level if the underlying associations were strong or moderate, i.e. they had an $\mathrm{r} \geq 0.22$. $P$-values presented in this paper are two-tailed.

\section{RESULTS}

Subjects' mean ( \pm SD) BMI was $22.3 \pm 3.6 \mathrm{~kg} / \mathrm{m}^{2}$ (range 15.4-35.9). Fifteen males and 9 females (20.4\% of all participants) were overweight $\left(25 \mathrm{~kg} / \mathrm{m}^{2} \leq\right.$ BMI $\left.<30 \mathrm{~kg} / \mathrm{m}^{2}\right)$ whereas 4 males and one female $(4.2 \%$ of all) were classified ${ }^{21}$ as obese (BMI $\geq 30 \mathrm{~kg} / \mathrm{m}^{2}$ ).

Descriptive statistics of the study variables for females and males are shown in Table 1. Females, compared to males, had lower BMI $(P=0.001)$ and FFM 
values $(P<0.001)$ and a higher sum of four skinfolds $(P<0.01)$ and $\%$ FM values $(P<0.001)$. Additionally, females had higher plasma leptin concentrations, lower sOB-R concentrations and higher leptin/sOB-R values (each $P<0.001$, by unpaired $t$-test).

The genotype distribution and allele frequencies for the $-2548 \mathrm{G} / \mathrm{A}$ and the $-188 \mathrm{C} / \mathrm{A}$ polymorphisms are presented in Table 2 . Both polymorphisms were in Hardy-Weinberg equilibrium. Only nine individuals were heterozygous for the rare $-188 \mathrm{~A}$ allele of the $-188 \mathrm{C} / \mathrm{A}$ polymorphism and no one homozygous for this allele (-188A allele frequency: 0.04, Table 2). The estimated $-188 \mathrm{~A}$ allele frequency in our Greek sample is less than that found among obese and lean Finnish adults ${ }^{17}$. This polymorphic locus, which, based on data from previously published observations, was used as a negative control in this study, was associated with neither obesity nor leptin levels as expected (data not shown). The $-2548 \mathrm{G} / \mathrm{A}$ polymorphism was common among the study participants, with the $-2548 \mathrm{~A}$ allele being the less frequent allele (-2548A allele frequency: 0.47 , Table 2 ). There were no differences of genotype and allele frequencies of this polymorphism between genders, nor were there differences in allele frequency between subjects with BMI $\leq 25 \mathrm{~kg} / \mathrm{m}^{2}$ $(\mathrm{n}=89)$ and the group of overweight subjects $(\mathrm{BMI}>$ $25 \mathrm{~kg} / \mathrm{m}^{2}, \mathrm{n}=29$ ) (data not shown).

In the 118 young Greek subjects, analysis of covariance (ANCOVA) of several adiposity-related variables across genotypes of the $-2548 \mathrm{G} / \mathrm{A}$ polymorphism revealed no significant association of the -2548 polymorphic locus with body composition parameters, in-
Table 2. Genotype distribution and allele frequencies for the leptin gene promoter $-2548 \mathrm{G} / \mathrm{A}$ and $-188 \mathrm{C} / \mathrm{A}$ polymorphisms in a group of healthy Greek subjects $(n=118)$.

\begin{tabular}{cccc}
\hline \multicolumn{2}{c}{-2548G/A polymorphism } & \multicolumn{2}{c}{-188C/A polymorphism } \\
\hline Genotypes & $\%(\mathrm{n})$ & Genotypes & $\%(\mathrm{n})$ \\
$\mathrm{G} / \mathrm{G}$ & $29.7(35)$ & $\mathrm{C} / \mathrm{C}$ & $92.4(109)$ \\
$\mathrm{G} / \mathrm{A}$ & $46.6(55)$ & $\mathrm{C} / \mathrm{A}$ & $7.6(9)$ \\
$\mathrm{A} / \mathrm{A}$ & $23.7(28)$ & $\mathrm{A} / \mathrm{A}$ & 0.0 \\
Alleles & & Alleles & \\
$\mathrm{G}$ & 53.0 & $\mathrm{C}$ & 96.2 \\
$\mathrm{~A}$ & 47.0 & $\mathrm{~A}$ & 3.8 \\
\hline
\end{tabular}

cluding BMI, fat mass, $\mathrm{W} / \mathrm{H}$ ratio and sum of four skinfolds, or with plasma total leptin levels (data not shown). However, we detected an association of borderline significance between the $-2548 \mathrm{G} / \mathrm{A}$ genotype and the ratio leptin/sOB-R $(P=0.06$ by ANCOVA adjusting for gender, age and fat mass), with subjects homozygous for the less frequent $-2548 \mathrm{~A}$ allele (A/A genotype) exhibiting lower leptin/sOB-R values compared to those with the G/G or G/A genotypes. In all further analyses, subjects with the A/A genotype were compared to subjects carrying at least one $-2548 \mathrm{G}$ allele, as leptin/sOB-R values were similar between the $\mathrm{G} / \mathrm{A}$ and $\mathrm{G} / \mathrm{G}$ subjects (i.e. a recessive model for $-2548 \mathrm{~A})$. The results of these analyses are shown in Table 3. Mean leptin/sOB-R values, adjusted for fat mass, age and gender, were approximately $50 \%$ lower in $\mathrm{A} / \mathrm{A}$ subjects than in $\mathrm{G} / \mathrm{A}$ and $\mathrm{G} / \mathrm{G}$ subjects $(0.44$ \pm 0.17 vs. $0.85 \pm 0.10, P=0.05)$. Similar models showed statistically significant differences in females,

Table 1. Descriptive characteristics of the study participants $(n=118)$.

\begin{tabular}{lccccc}
\hline & \multicolumn{2}{c}{ Females $(\mathbf{n}=\mathbf{6 2})$} & \multicolumn{2}{c}{ Males $(\mathbf{n}=\mathbf{5 6})$} & \\
Variable & Mean \pm SD & $($ Range $)$ & Mean \pm SD & $($ Range $)$ & P-value \\
\hline Age $(\mathrm{yr})$ & $17.5 \pm 1.6$ & $(14-26)$ & $17.8 \pm 1.8$ & $(15-25)$ & NS \\
BMI $\left(\mathrm{kg} / \mathrm{m}^{2}\right)$ & $21.3 \pm 3.1$ & $(16.2-30.1)$ & $23.4 \pm 3.8$ & $(15.4-35.9)$ & 0.001 \\
Sum of skinfolds $(\mathrm{mm})$ & $48.7 \pm 17.4$ & $(23.0-95.0)$ & $38.6 \pm 18.4$ & $(17.0-106.0)$ & $<0.01$ \\
FFM $(\mathrm{kg})$ & $39.5 \pm 3.8$ & $(28.4-47.9)$ & $59.6 \pm 6.1$ & $(45.4-72.5)$ & $<0.001$ \\
FM $(\mathrm{kg})$ & $15.5 \pm 4.8$ & $(7.9-29.1)$ & $13.3 \pm 7.3$ & $(3.0-35.0)$ & NS \\
FM $(\%)$ & $27.6 \pm 5.0$ & $(17.6-38.4)$ & $17.3 \pm 6.9$ & $(6.0-32.6)$ & $<0.001$ \\
Leptin $(\mathrm{ng} / \mathrm{ml})$ & $9.7 \pm 6.0$ & $(2.1-30.0)$ & $3.2 \pm 2.6$ & $(1.2-12.8)$ & $<0.001$ \\
sOB-R $(\mathrm{ng} / \mathrm{ml})$ & $27.2 \pm 29.1$ & $(4.4-108.4)$ & $50.2 \pm 39.8$ & $(4.4-164.2)$ & $<0.001$ \\
Leptin/sOB-R & $1.27 \pm 1.44$ & $(0.05-5.69)$ & $0.19 \pm 0.26$ & $(0.03-1.47)$ & $<0.001$ \\
\hline Compris
\end{tabular}

Comparisons between males and females by unpaired $t$-test 
Table 3. Means and SE of the adiposity-related variables adjusted for gender and/or age, plus fat mass (kg) for leptin, sOB-R and the ratio leptin/sOB-R, according to leptin gene promoter -2548G/A genotype in healthy Greek subjects.

\begin{tabular}{|c|c|c|c|c|c|c|c|c|c|c|}
\hline \multirow[b]{2}{*}{ Variable } & \multirow[b]{2}{*}{ Genotype } & \multicolumn{3}{|c|}{ All subjects $(n=118)$} & \multicolumn{3}{|c|}{ Females $(n=62)$} & \multicolumn{3}{|c|}{ Males (n=56) } \\
\hline & & (n) & Mean $\pm \mathrm{SE}$ & $P$ & (n) & Mean $\pm \mathrm{SE}$ & $P$ & (n) & Mean $\pm \mathrm{SE}$ & $P$ \\
\hline \multirow[t]{2}{*}{ BMI $\left(\mathrm{kg} / \mathrm{m}^{2}\right)$} & $\mathrm{G} / \mathrm{G}+\mathrm{G} / \mathrm{A}$ & (90) & $22.4 \pm 0.4$ & 0.52 & $(48)$ & $21.4 \pm 0.5$ & 0.59 & $(42)$ & $23.6 \pm 0.6$ & 0.52 \\
\hline & $\mathrm{A} / \mathrm{A}$ & (28) & $21.9 \pm 0.6$ & & (14) & $20.8 \pm 0.8$ & & (14) & $22.9 \pm 1.0$ & \\
\hline \multirow[t]{2}{*}{$\mathrm{FM}(\mathrm{kg})$} & $\mathrm{G} / \mathrm{G}+\mathrm{G} / \mathrm{A}$ & & $14.6 \pm 0.6$ & 0.45 & & $15.7 \pm 0.7$ & 0.42 & & $13.6 \pm 1.1$ & 0.54 \\
\hline & $\mathrm{A} / \mathrm{A}$ & & $13.7 \pm 1.1$ & & & $14.5 \pm 1.3$ & & & $12.3 \pm 1.9$ & \\
\hline \multirow[t]{2}{*}{$\mathrm{FM}(\%)$} & $\mathrm{G} / \mathrm{G}+\mathrm{G} / \mathrm{A}$ & & $22.9 \pm 0.6$ & 0.50 & & $27.8 \pm 0.7$ & 0.41 & & $17.5 \pm 1.0$ & 0.59 \\
\hline & $\mathrm{A} / \mathrm{A}$ & & $22.0 \pm 1.1$ & & & $26.6 \pm 1.4$ & & & $16.4 \pm 1.8$ & \\
\hline \multirow[t]{2}{*}{ Leptin $(\mathrm{ng} / \mathrm{ml}){ }^{*}$} & $\mathrm{G} / \mathrm{G}+\mathrm{G} / \mathrm{A}$ & & $6.8 \pm 0.4$ & 0.30 & & $10.5 \pm 0.6$ & 0.23 & & $3.2 \pm 0.3$ & 0.74 \\
\hline & $\mathrm{A} / \mathrm{A}$ & & $6.1 \pm 0.7$ & & & $8.5 \pm 1.1$ & & & $3.4 \pm 0.4$ & \\
\hline \multirow[t]{2}{*}{$\mathrm{sOB}-\mathrm{R}(\mathrm{ng} / \mathrm{ml}){ }^{*}$} & $\mathrm{G} / \mathrm{G}+\mathrm{G} / \mathrm{A}$ & & $36.9 \pm 3.5$ & 0.08 & & $25.6 \pm 3.8$ & 0.05 & & $50.0 \pm 6.2$ & 0.58 \\
\hline & $\mathrm{A} / \mathrm{A}$ & & $41.9 \pm 6.4$ & & & $32.9 \pm 7.2$ & & & $50.6 \pm 10.7$ & \\
\hline \multirow[t]{2}{*}{ Leptin/sOB-R* } & $\mathrm{G} / \mathrm{G}+\mathrm{G} / \mathrm{A}$ & & $0.85 \pm 0.10$ & 0.05 & & $1.42 \pm 0.13$ & 0.02 & & $0.20 \pm 0.04$ & 0.53 \\
\hline & $\mathrm{A} / \mathrm{A}$ & & $0.44 \pm 0.17$ & & & $0.74 \pm 0.25$ & & & $0.15 \pm 0.06$ & \\
\hline
\end{tabular}

* Natural logarithmic transformations were performed before analysis.

but not in males (Table 3). Compared to carriers of the $-2548 \mathrm{G}$ allele, female subjects with the A/A genotype had higher age and fat mass adjusted mean plasma concentrations of sOB-R $(32.9 \pm 7.2$ vs. $25.6 \pm$ $3.8 \mathrm{ng} / \mathrm{ml}, P=0.05$ ), and significantly lower (approx. $50 \%)$ leptin/sOB-R values $(0.74 \pm 0.25$ vs. $1.42 \pm 0.13$, $P=0.02)$. They also exhibited lower levels of plasma total leptin (approx. 20\%), but this difference did not achieve statistical significance (Table 3 ). The above results were similar when fat mass was substituted for BMI in the statistical analyses, or after adjustment for exercise and smoking status.

To further explore the contribution of the $-2548 \mathrm{G} /$ A polymorphism in explaining the variation in leptin/ sOB-R values, multiple regression analyses were performed, using as independent variables genotype, fat mass and gender. Results revealed that genotype, fat mass and gender are significant and independent predictors of the ratio leptin/sOB-R in this group of healthy Greek subjects, explaining $40 \%$ of the variance (Table 4). In additional models, an interaction term involving fat mass and genotype (fat mass $\mathrm{x}$ genotype), or gender and genotype (gender x genotype), was introduced to the above multiple regression model, in order to ascertain whether there is an interaction between these factors in predicting free leptin index. We found a significant association of the ratio leptin/sOB-R with the interaction of genotype and fat mass ( std beta $=0.92, P=0.02$ ) in addition to a signif-
Table 4. Results of the regression analysis performed to test the effect of the leptin gene promoter -2548G/A genotype on free leptin index adjusted to fat mass (or BMI) and gender.

\begin{tabular}{lcccc}
\hline & \multicolumn{4}{c}{ Dependent variable: Leptin/sOB-R } \\
\cline { 2 - 5 } Predictors & Beta & $\mathbf{~ r ~}$ & P-value & Adj $\mathbf{R}^{\mathbf{2}}$ \\
\hline -2548G/A genotype & 0.14 & 0.18 & 0.05 & \\
Fat mass & 0.43 & 0.48 & $<0.001$ & 0.398 \\
Gender & 0.38 & 0.44 & $<0.001$ & \\
\hline
\end{tabular}

Beta: Standardized regression coefficient, r: partial correlation coefficient

icant association with gender ( $\mathrm{std}$ beta $=0.38$, $P<0.001$ ). Similarly, in addition to fat mass (std beta $=0.43, P<0.001$ ), an interaction of genotype and gender in predicting free leptin index (std beta $=0.81$, $P=0.03$ ) was observed in the entire study sample. Moreover, the addition of an interaction term explains a higher percentage of variance indicating that an interaction of the factors studied may have physiological significance. In females only, both the $-2548 \mathrm{G} / \mathrm{A}$ genotype (std beta $=0.19, P=0.02$ ) and fat mass (std beta $=0.74, P<0.001)$ are significant predictors of the ratio leptin/sOB-R, explaining $60 \%$ of the variance. In contrast, a significant association of leptin/sOB-R with fat mass (std beta $=0.40, P=0.002$ ) but not genotype (std beta $=0.08, P=0.52$ ), was observed in males, indicating that this polymorphism does not play a role of comparable importance in men. 


\section{DISCUSSION}

The presence of polymorphisms in the promoter region of the human leptin gene has recently been associated with variations in circulating leptin levels. Since conflicting data on the potential importance of the common $-2548 \mathrm{G} / \mathrm{A}$ promoter variant have previously been published ${ }^{12-15}$, we explored the associations between this genetic variant and plasma total leptin levels, as well as soluble leptin receptor (sOB-R) and free leptin, in a Greek sample of healthy subjects.

The leptin gene promoter $-2548 \mathrm{G} / \mathrm{A}$ polymorphism was recently shown to be associated with extreme obesity in North American Caucasian women ${ }^{16}$, in whom the $\mathrm{G}$ allele was more frequent in 125 unrelated extremely obese $\left(B M I \geq 40 \mathrm{~kg} / \mathrm{m}^{2}\right)$ than 86 averageweight $\left(\mathrm{BMI}<27 \mathrm{~kg} / \mathrm{m}^{2}\right)$ subjects $(0.65$ vs. 0.49 , $P=0.017)$; however, leptin levels were not measured in that study. Mammés et $\mathrm{al}^{13}$ also reported a significantly higher prevalence of $\mathrm{G}$ (or less A) alleles in overweight (BMI $\geq 27 \mathrm{~kg} / \mathrm{m}^{2}$ ) than normal weight subjects ( $\mathrm{G}$ allele frequency 0.64 vs. $0.54, P<0.01$ ), although the higher frequency of the $G$ allele in overweight subjects was significant in men but not in women. In our study population, $\mathrm{G}$ and A allele frequencies ( $\mathrm{G}$ allele frequency: 0.53 ) are similar to those reported for normal Caucasians in the previous two studies $^{13,16}$. However, no significant differences in genotype or allele frequencies were detected between normal weight and overweight (BMI $>25 \mathrm{~kg} / \mathrm{m}^{2}$ ) subjects (data not shown), but a small proportion of our sample was extremely obese. Our finding is in agreement with a study by Le Stunff et $\mathrm{al}^{15}$ showing a comparable genotype distribution between two independent Caucasian cohorts of obese girls, a group of related subjects of normal weight and a group of 116 lean Caucasian adults. Furthermore, we found no association of the $-2548 \mathrm{G} / \mathrm{A}$ polymorphism with common obesity-related variables, including BMI, fat mass and percent fat mass, by univariate analysis.

Previous studies have shown both increased ${ }^{13,14}$ and decrease ${ }^{15}$ levels of circulating leptin in subjects carrying the A/A genotype of the leptin gene promoter $-2548 \mathrm{G} / \mathrm{A}$ polymorphism. Hoffstedt et al ${ }^{14}$ investigated whether this polymorphism influences gene expression and adipose tissue production of leptin in 39 non-obese women. They found that women with the A/A genotype had higher serum leptin levels adjusted for BMI $(P=0.03)$ and significantly higher adipose tissue lep- tin secretion rates $(P=0.02)$ and mRNA levels $(P=0.01)$ than did carriers of the $-2548 \mathrm{G}$ allele. In the study by Mammés et $\mathrm{al}^{13}$, men with the A/A genotype also exhibited higher serum total leptin levels than did male carriers of the $\mathrm{G}$ allele $(15-20 \%$ higher, $P=0.05)$, but in contrast to the previous study no similar effect of genotype was observed in women of this study (females with the A/A genotype were shown to have approx. 20\% lower leptin levels, but this effect did not achieve statistical significance, $P=0.1$ ). The opposite genotypic effect was reported in the study by Le Stunff et $\mathrm{al}^{15}$. In this study, obese girls with the A/A genotype exhibited 20-25\% lower leptin values for a given fat mass than those of other genotypes $(P<0.02)$. Although the reasons for the discordance of findings in these studies are unknown, they could be attributed to age related modifications in leptin physiology and/or gender specific effects of the polymorphism.

Our results in a homogeneous sample of young healthy subjects support the hypothesis that the $-2548 \mathrm{G} / \mathrm{A}$ polymorphism is associated with free circulating leptin levels, after adjustment for fat mass (or BMI), in a gender specific manner. More specifically, free leptin levels adjusted for fat mass were approx. 50\% lower in female, but not male, subjects with the A/A genotype compared to those with the $\mathrm{G} / \mathrm{G}$ and $\mathrm{G} / \mathrm{A}$ genotypes $(P=0.02)$. Similarly, specific interaction models indicated a significant interaction between gender and genotype, as well as fat mass and genotype, in predicting circulating free leptin levels. Although a similar trend was also observed for total leptin levels (i.e. mean plasma total leptin levels adjusted for fat mass were approx. 20\% lower in females with the A/A genotype than in G/A and G/G subjects), this trend did not achieve statistical significance. However, females with the A/A genotype had statistically significant higher fat mass adjusted mean sOB-R levels than did female carriers of the $-2548 \mathrm{G}$ allele (approx. $30 \%$ higher, $P=0.05$ ). We have previously shown in observational and interventional studies in humans that circulating sOB-R levels are regulated by gender, adiposity, sex steroids and leptin ${ }^{19}$. Most importantly, leptin was found to reciprocally regulate circulating levels of its own binding protein ${ }^{19}$, which suggests that the binding protein may be up-regulated in states of decreased leptin expression. In this respect, the higher sOB-R levels observed in female subjects with the A/A genotype may be secondary to the lower 
total letpin levels, which in turn influences free leptin levels. In the study by Le Stunff et al,${ }^{15}$ obese girls with the A/A genotype also exhibited lower serum total leptin levels of similar magnitude with our study, but in that study the difference achieved statistical significance (absolute values; $P=0.016$, and after normalization to body fat; $P=0.017$ ) probably due to the study's relatively larger size and high power. Moreover, in our study the free and presumably biologically more active leptin levels were even lower (approx. $50 \%$ ) than total leptin levels, suggesting that this is of physiological significance.

Our study provides no direct insights into the mechanisms responsible for the observed genotypic effects. The leptin gene promoter -2548 polymorphic locus does not correspond to a known binding site sequence for transcription factors and the $-2548 \mathrm{G} \rightarrow \mathrm{A}$ substitution does not modify or create any already known regulating $\operatorname{site}^{13,14}$. It has been proposed that $-2548 \mathrm{G} /$ A polymorphism may be located in a regulating site specific for leptin as yet unidentified ${ }^{13}$. In this respect, it has recently been shown that nuclear factors extracted from both U937 cells and subcutaneous adipocytes (the nature of which is at present unknown) bind with higher affinity to the $-2548 \mathrm{~A}$ allele ${ }^{14}$, which indicates that the -2548 polymorphic site may modify the transcription rate of the leptin gene. This, however, does not exclude the possibility that the polymorphism is in linkage disequilibrium with other regulatory sequences influencing transcription of the leptin gene. The effect modification by gender shown in this study raises the possibility of an interaction between this polymorphism and an Estrogen Response Element of the leptin gene promoter. This hypothesis remains to be conclusively proven by further studies.

The power of the entire study was appropriately high $(80 \%)$ to demonstrate statistically significant associations that could be of clinical importance (i.e. those with an $r \geq 0.22$ ). The study was not powered for subgroup analysis but the fact that the associations studied in females are of statistical significance provides reassurance regarding the validity of the data presented herein.

In summary, we have shown that the $-2548 \mathrm{G} / \mathrm{A}$ polymorphism in the promoter region of the human leptin gene is associated with plasma free leptin but not obesity indices in healthy subjects. Moreover, our data point to an interaction of gender and genotype, as well as fat mass and genotype in predicting free leptin levels. Thus, these observations not only confirm but also extend previously published data.

\section{ACKNOWLEDGMENTS}

The authors would like to thank Dr. Dorothy Klimis-Zacas for her contribution in designing the original research project and Dr. Evangellos Polychronopoulos for his assistance with blood draws.

This work was supported in part by a grant (KA0008) from Harokopio University and an R-01 DK 58785 award to Christos S. Mantzoros.

\section{REFERENCES}

1. Maffei M, Halaas J, Ravussin E, et al, 1995 Leptin levels in human and rodent: measurement of plasma leptin and ob RNA in obese and weight-reduced subjects. Nature Med 1: 1155-1161.

2. Considine RV, Sinha MK, Heiman ML, et al, 1996 Serum immunoreactive-leptin concentrations in normalweight and obese humans. N Engl J Med 334: 292-295.

3. Lahlou N, Landais P, De Boissieu D, Bougnères PF, 1997 Circulating leptin in normal children and during the dynamic phase of juvenile obesity: relatio to body fatness, energy metabolism, caloric intake, and sexual dimorphism. Diabetes 46: 989-993.

4. Sinha MK, Opentanova I, Ohannesian JP, et al, 1996 Evidence of free and bound leptin in human circulation: studies in lean and obese subjects and during short-term fasting. J Clin Invest 98: 1277-1282.

5. Houseknecht KL, Mantzoros CS, Kuliawat R, Hadro E, Flier JS, Kahn BB, 1996 Evidence for leptin binding to proteins in serum of rodents and humans: modulation with obesity. Diabetes 45: 1638-1643.

6. Diamond FB, Eichler DC, Duckett G, Jorgensen EV, Shulman D, Root AW, 1997 Demonstration of a leptin binding factor in human serum. Biochem Biophys Res Commun 233: 818-822.

7. Mantzoros CS, 1999 The role of leptin in human obesity and disease: a review of current evidence. Ann Intern Med 130: 671-680.

8. Friedman JM, Halaas JL, 1998 Leptin and the regulation of body weight in mammals. Nature 395: 763-769.

9. Zhang Y, Proenca R, Maffei M, Barone M, Leopold L, Friedman JM, 1994 Positional cloning of the mouse obese gene and its human homologue. Nature 372: 425-432.

10. Montague CT, Farooqi IS, Whitehead JP, et al, 1997 Congenital leptin deficiency is associated with severe early-onset obesity in humans. Nature 387: 903-908.

11. Stobel A, Issad T, Camoin L, Ozata M, Strosberg DA, 1998 A leptin missense mutation associated with hypogonadism and morbid obesity. Nat Genet 18: 213-215.

12. Mammés O, Betoulle D, Aubert R, et al, 1998 Novel poly- 
morphisms in the 5' region of the LEP gene. Diabetes 47: 487-489.

13. Mammés O, Betoulle D, Aubert R, Herbeth B, Siest G, Fumeron F, 2000 Association of the G-2548A polymorphism in the 5 ' region of the LEP gene with overweight. Ann Hum Genet 64: 391-394.

14. Hoffstedt J, Eriksson P, Mottagui-Tabar S, Arner P, 2002 A polymorphism in the leptin gene promoter region ($2548 \mathrm{~g} / \mathrm{a}$ ) influences gene expression and adipose tissue secretion of leptin. Horm Metab Res 34: 355-359.

15. Le Stunff C, Le Bihan C, Schork NJ, Bougneres P, 2000 A common promoter variant of the leptin gene is associated with changes in the relationship between serum leptin and fat mass in obese girls. Diabetes 49: 2106-2200.

16. Li WD, Reed DR, Lee JH, et al, 1999 Sequence variants in the 5' flanking region of the leptin gene are associated with obesity in women. Ann Hum Genet 63: 227-234.

17. Oksanen L, Kainulainen K, Heiman M, Mutsajoki P, Kauppinen-Mäkelin R, Kontula K, 1997 Novel polymorphism of the human ob gene promoter in lean and morbidly obese subjects. Int J Obes Relat Metab Disord 21:
489-494.

18. Yiannakouris N, Yannakoulia M, Melistas L, Chan JL, Klimis-Zacas D, Mantzoros CS, 2001 The Q223R polymorphism of the leptin receptor (LEPR) gene is significantly associated with obesity and predicts a small percentage of body weight and body composition variability. J Clin Endocrinol Metab 86: 4434-4439.

19. Chan JL, Bluher S, Yiannakouris N, Suchard MA, Kratzsch J, Mantzoros CS, 2001 Regulation of circulating soluble leptin receptor levels by gender, adiposity, sex steroids, and leptin: observational and interventional studies in humans. Diabetes 51: 2105-2112.

20. Lammert A, Kiess W, Bottner A, Glasow A, Kratzsch J, 2001 Soluble leptin receptor represents the main binding activity in human blood. Biochem Biophys Res Commun 283: 982-988.

21. Cole TJ, Bellizzi MC, Flegal KM, Dietz WH, 2000 Establishing a standard definition for child overweight and obesity worldwide: international survey. BMJ 320: 12401243. 